\title{
Running a Successful Textile Diploma Course in A Remote Indian Town - A Case Study
}

\author{
Pramod Raichurkar $^{1}$, Vishnu Dorugade ${ }^{2}$, Pradeep Waychal $^{3}$ \\ ${ }^{1,2,3}$ SVKM's NMIMS, Shirpur, India \\ 33radeep.waychal@gmail.com
}

\begin{abstract}
Indian Textile industry is unique in many ways. It is the second largest employer and depends heavily on the largest employer - agriculture. It has been successful in automating most of its operations. So, instead of employing unskilled labor, it is now looking for skilled labor and facing significant challenges in finding them - even though the national unemployment has been hovering at around $9 \%$. The situation demanded a different approach such as setting up textile training courses in a remote area where employment is a larger issue and working closely with the industry to develop highly employable graduates. The paper describes a successful case study of setting up a four year diploma course in close collaboration with the industry in a remote town of Shirpur in North Maharashtra (India). That required a team of faculty that could inspire confidence in the industry personnel and adopting progressive educational methods such as active learning and mentoring. The school was started in 2007 and has produced 200 diploma holders with cent percent placement. This is far above similar other institutes. These students from rural and semi-rural area are fetching salaries that are higher than even graduate engineers. Thus the experiment has succeeded in its twin objectives of rural development and workforce development for one of the most critical industry of the country.
\end{abstract}

Pradeep Waychal

SVKM's NMIMS, Shirpur, India

pradeep.waychal@gmail.com

\section{Introduction}

The essence of education is in transforming students from an adolescent to a budding professional. Going by the current reports on employability, in general, and in India, in particular; the education system seems to be failing. The educators have to focus on the pedagogical frameworks and methodologies to bring in the change. The paper describes one such attempt undertaken at SVKM (Shri Vile Parle Kelvani Mandal)'s NMIMS (Narsee Monjee Institute of Management Studies) University at Shirpur. Its center of textile functions has developed a framework around industry partnership, mentoring and active learning and succeeded in transforming rural and semi-rural SSC (Secondary School Certificate) pass students into excellent professionals. It right-to-fame is justified by the cent percent placement with some of the students claiming salary packages more than graduate engineers. The major contribution of the paper is describing the case study so that others can benefit from it.

The next section provides background by describing the Indian textile industry, the Centre of Textile Functions (CTF) and it's Diploma in Textile Technology Program. Then we discuss architecture of the program and present the results. We end with concluding remarks.

\section{Background}

Indian textile industry is one of the leading textile industries in the world. It largely depends upon textile manufacturing and exports and contributes about 14\% 
to industrial production, $4 \%$ to the GDP and $17 \%$ to the country's export earnings. The industry provides direct employment to over 35 million people thereby becoming the second largest provider of employment after agriculture. The global technical textile industry is estimated at US\$127 billion and its size in India is pegged at US $\$ 11$ billion. Further, India has potential to increase its textile and apparel share in the world trade from current level of $4.5 \%$ to $8 \%$ and reach US $\$ 80$ billion by 2020 . This potential for growth has a direct bearing on the huge requirement of technical personnel. Industry is striving to achieve excellence in terms of better quality, productivity and turnaround time. Towards that, it is using optimized quality controls and appropriate technologies. These things will succeed in providing returns only if there is a well-qualified and efficient workforce.

\section{Centre of Textile Functions (CTF)}

To fulfill that requirement, we have set up the Centre of Textile Functions (CTF). It has been in operation since 2007 with a vision of being a vibrant and innovative center for education, research and executive training in the field of textile technology. It aims at developing a cadre of socially responsive textile technocrats by providing quality education to the rural and urban youth. It runs a four year program in Diploma in Textile Technology. The center works closely with our group's most modern textile park that houses many organizations such as Priyadarshini Sahakari Soot Girni Limited (PSSGL) that operates a variety of textile processes such as Ginning, spinning, knitting, weaving, wet processing and garmenting. This partnership helps in updating student's technical knowledge as per changing industry requirements. We believe that the industrial exposure helps students to become better professionals.

\section{Diploma in Textile Technology Program}

This four year post SSC diploma program is the flagship program run by the center. Its main focus is to bridge the gap between education and industry by leveraging industry partnership supported by mentoring and active learning processes. We developed the program objective and program outcomes in line with the center vision and the industry inputs. While the group industry houses are fully leveraged in the program; other leading industry houses also participate in providing internship, inputs to the program curriculum and placement opportunities.

\section{Program Architecture}

The program was architected around three principles - industry partnership, mentoring and active learning called as "see and Learn" and "work and learn". It is depicted in figure 1.

\subsection{Industry Partnership}

The industry institute partnership is of paramount importance in all the professional programs. It is practiced in the best possible way in medical education by associating a hospital with a college. The partnership programs have been on the rise in engineering programs. Dallas, et al. have described a 15 year long-standing and successful and symbiotic university-industry partnership in semiconductor device engineering between Texas Tech University and Texas Instruments. Aggarwal, has described another long standing successful program between Gammon University and GE (General Electric) Transportation. The program has combined academic program with application training on actual industrial problems and has been providing a steady stream of outstanding professionals to GE Transportation. Baukal, et al. also have described some important benefits of this industry-university partnership to ORU (Oral Roberts University) students, and JZ (John Zinc Company). Danielson and Roberts have described successful offering of BS in Engineering for a major industrial partner.

Rangan and Natarajarathinam have argued that Internships can be effectively used for better assessing potential of the interns and utilized as an extended job interview. It helps industry as interns would have had organization specific training that increases fitment in its culture facilitating success. Angolia, et al. have proposed a model to leverage industry partnership and spelled out the benefits of the partnerships in terms of facilitating students' entry in the work force with confidence and through understanding of the job requirements and company culture.

There are studies about macro level industry partnerships, too. Creasy and Fuehne have implemented a successful Partnership between Community, Industry, and Academia. This integrates high school, college and local industry. Erin, et al. suggest scaling of the collaboration at state level with the state governors playing active roles.

Our course in diploma in technical technology has 
been running in a small town Shirpur in Northern Maharashtra in India. The traditional cotton growing area has resulted in various textile industrial houses. Since most of the businesses and the academic institute are mentored by the same leader; the partnership was natural. It was nurtured very well by the next level leaders on both the sides.

The students in their second and third years spend half of the academic time in the industry for their lab work enabling them access and understand technologies in use. The local as well as national industry houses provide them internship opportunities in the summers. This exposure and access to helps them to take up real life industry projects that get deployed and that accentuate the learning and makes them job ready. Moreover, many industry experts regularly visit the center and engage students in formal and informal sessions.

The industry partnership helped in developing the course curriculum and training module for various skills required by the Industry. It helped to impart those skills right on the shop floors and made students aware of the real life problems and approaches to find out solutions. The partnership exposed faculty to the industry realities so that they can teach theory courses appropriately. The partnership allowed students to interact with research institutes and to improve process technology in various segments such as weaving, knitting garmenting and chemical processing. Some industry houses encouraged students and faculty by sponsoring them for various seminars and conference to present their solutions.

\subsection{Active Learning}

Extensive research has been done on the efficacy of active learning in engineering education. Prince has defined active learning as any instructional method that engages students in the learning process. He has contrasted that with the traditional lecture where students passively receive information from the instructor. Bonwell and Eison conclude that active learning leads to better student attitudes and improvements in students' thinking and writing. Lamancusa, Zayas, Soyster, Morell, and Jorgensen, (2008) argue that personal experience on real problems develops skills and knowledge that are far more memorable and transferable than passive lectures; they quote Albert Einstein who said "the only source of knowledge is experience."

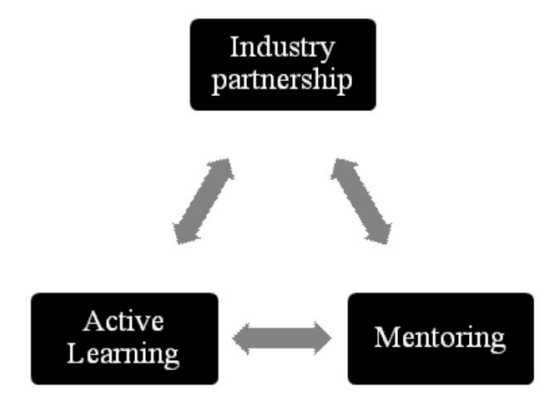

Figure 1: Architecture of the Program

The program - by virtue of extensive exposure to the shop floor and superb facilitation by the industry personnel to help students understand and solve problems - had significant elements of active learning. They are referred to as "See \& Learn" and "Work \& Learn".

\subsection{Mentoring}

Wadia-Fascetti, S. and Leventman $\square$ oint out that the number of formal metoring programs has increased dramatically and define mentoring as relationship where individuals work with each other to foster growth, goal achievement, and selfconfidence. errari ad concluded that idividualswith a mntor in life and at school ensurd stronger perceptions of their institution's educational mission, a greater sense of campus altruism, and acommitment to lifelong engagement in education than with mentors from life alone or students with no mentor Campbell and Campbell found that a the end of the one $\square$ year mentoring experience, mentored students had a higher GPA, completed more units, and had a higher retention rate.

We defined mentoring as a friendly relationship between a faculty and a student to enhance student's career by developing skills and knowledge. The faculty mentor works in tandem with industry personnel to aid the all-round development process of students. The mentors appreciate the problems that students face and guide them to facilitate appropriate solutions. The faculty mentors are supported by the industry professionals by providing feedback on students' shop floor behavior including ability to identify problems and solutions thereof. They also propose development of relevant training modules based on analysis of performance of the complete cohort. Further, the mentors stay connected with their mentees even after graduation both to offer help as well as seek feedback in order to improve the program. 
Overall, the program is designed to give students not only the fundamentals of modern textile engineering, but also introduction in a variety of subjects, both technical and nontechnical, so as to develop a broader view leading to a more intelligent approach to industrial and organizational problems

\section{Results}

We firmly believe that the program is a runaway success. A four year diploma program that caters to rural population and consistently achieves cent percent placement is unheard of. Moreover, the salary packages are competing with that of graduate engineers. The center is frequently visited by who's who of the industry - even though - the campus is so remotely placed. The success is due to both choosing the right area in terms of textile technology in Shirpur area and efforts of the entire team. The progress graphs of the center are given below in figure 2;
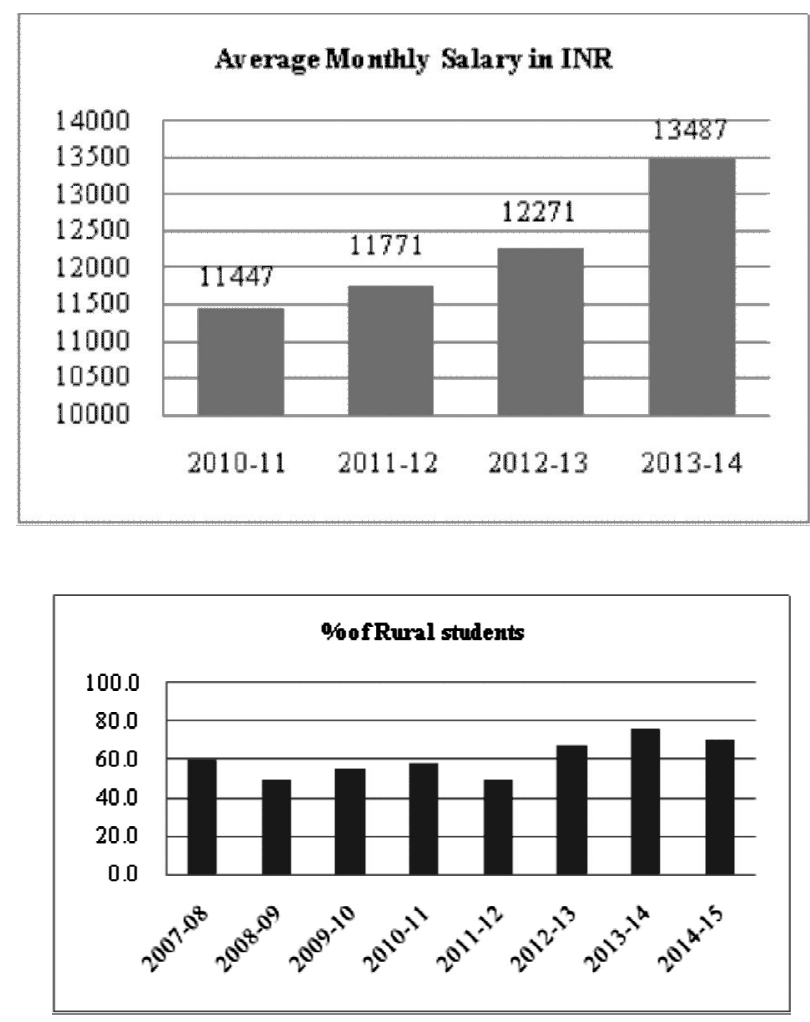

Figure 2: Progress Graphs of the CTF

\section{Concluding Remarks}

While the employability problem has been staring at Indian engineering education system, we have successfully developed a four year diploma post SSC for rural and semi-rural students. We have managed them to develop those adolescents into competent professionals resulting in 100 percent placements with salary packages competitive with graduate engineers. The course hinges on industry-institute partnership, mentoring and active learning. We could manage the industry partnership easily due to our group having many textile businesses in the area. Many other institutes may not have that advantage.

The regulatory body - All India Council of Technical Education (AICTE) requires the diploma course to be of three years duration. We are developing the new curriculum by shortening the duration without compromising on the value of the course. Since the industry personnel associated with the program come largely from semi-rural areas, we believe that our students' transferrable skills require further development. We require bringing in some innovations on that front.

\section{References}

Aggarwal, M. (2010). "College-Industry Partnerships at its Best." Paper\#AC 52.

Angolia, e. a. (2014). Building Sustainable Industry Partnerships That Engage Faculty and Prepare JobReady Students. ASEE Annual Conference. Indianapolis.

Baukal, C., et al. (2010). Industry-University Partnership Case Study. American Society for Engineering Education Midwest Section Annual Conference.

Bonwell, C. C. and J. A. Eison (1991). Active Learning: Creating Excitement in the Classroom. 1991 ASHE-ERIC Higher Education Reports, ERIC.

Dallas, e. a. (2014). University-Industry Partnerships in Semiconductor Engineering ASEE Annual Conference. Indianapolis.

Danielson, e. a. (2013). A Successful Engineering Program-Corporate Partnership. ASEE Annual Conference. Atlanta.

Ferrari*, J. R. (2004). "Mentors in life and at school: impact on undergraduate prote' ge' perceptions of university mission and values." Mentoring \& Tutoring: Partnership in Learning 12(3): 295-305.

Fuehne, C. a. (2014). The Seamless Pathway: A Partnership Between Community, Industry, and Academia ASEE Annual Conference. Indianapolis.

Lamancusa, J. S., et al. (2008). "2006 Bernard M. Gordon Prize Lecture*: The Learning Factory: Industry?Partnered Active Learning." Journal of Engineering Education 97(1): 5-11. 
Lamos, E., et al. (2010). "A Sharper Focus on Technical Workers: How to Educate and Train for the Global Economy." NGACenter for Best Practices.

Natarajarathinam, R. (2014). How to Structure an Internship that is Great for the Intern and the Manager? .ASEE Annual Conference. Indianapolis.

Prince, M. (2004). "Does active learning work? A review of the research." Journal of Engineering Education 93(3): 223-231.

Wadia?Fascetti, S. and P. G. Leventman (2000). "E?Mentoring: A Longitudinal Approach to Mentoring Relationships for Women Pursuing Technical Careers." Journal of Engineering Education 89(3): 295-300. 